Rev. Adm. Saúde - Vol. 18, № 70, jan. - mar. 2018

http://dx.doi.org/10.23973/ras.70.71

ARTIGO ORIGINAL

\title{
Indicadores de avaliação da assistência farmacêutica na acreditação hospitalar
}

Indicators of evaluation of pharmaceutical assistance in hospital accreditation

\author{
Jaqueline Alves dos Santos ${ }^{1}$, Jane Beatriz Limberger ${ }^{2}$
}

\author{
1. Farmacêutica. Farmacêutica do HCS, Santa Maria RS \\ 2. Farmacêutica, mestre em química. Professora do curso de farmácia do Centro Universitário \\ Franciscano - UNIFRA, Santa Maria RS
}

\section{RESUMO}

Este trabalho tem por objetivo propor a implementação de indicadores de desempenho para avaliação da assistência farmacêutica em ambiente hospitalar, tendo em foco a garantia da qualidade. A metodologia empregada consistiu na observação das práticas relacionadas à assistência farmacêutica hospitalar e planejamento da implementação de indicadores de desempenho, baseada em um contexto previamente estabelecido pela própria investigação. Os dados foram coletados a partir de relatórios físicos e virtuais disponibilizados pela instituição, um hospital filantrópico da região central do Rio Grande do Sul. Os resultados foram coletados em dois momentos, um período observacional das atividades vinculadas à assistência farmacêutica hospitalar e, num segundo momento, a determinação de indicadores sugeridos para a qualificação da assistência farmacêutica hospitalar, contemplando o nome do indicador, o parâmetro observado, a fonte de evidência e estabelecimento de metas a serem cumpridas. Conclui-se que os indicadores de desempenho estão, intimamente, relacionados à garantia da qualidade $e$ excelência nos serviços de saúde, sendo notável a importância dos indicadores construídos e observados neste trabalho.

Palavras-chave: administração hospitalar, indicadores de serviços, assistência farmacêutica. 


\begin{abstract}
The objective of this study is to propose the implementation of performance indicators for the evaluation of pharmaceutical care in a hospital environment, focusing on quality assurance. The methodology used consisted of observing the practices related to pharmaceutical hospital care and planning the implementation of performance indicators, based on a context previously established by the research itself. The data were collected from physical and virtual reports provided by the institution, a philanthropic hospital in the central region of Rio Grande do Sul. The results indicate that the data were collected in two moments, an observational period of the activities related to hospital pharmaceutical care and, in a second the determination of suggested indicators for the qualification of hospital pharmaceutical care, including the name of the indicator, the observed parameter, the source of evidence and the establishment of targets to be met. It is concluded that the performance indicators are intimately related to quality assurance and excellence in health services, being remarkable the importance of the indicators constructed and observed in this work.
\end{abstract}

Keywords: hospital administration, indicators of health services, pharmaceutical services.

\title{
INTRODUÇÃO
}

A notificação dos erros de medicação em ambiente hospitalar é um instrumento importante para o gerenciamento da qualidade na assistência e segurança do paciente. Este tipo de evento tem sido objeto de preocupação dos gestores da saúde, e os erros de medicação, definidos como quaisquer erros no processo de prescrição, dispensação ou administração vêm chamando especial atenção (1). Estudo realizado pela Faculdade de Medicina da Universidade Federal de Minas Gerais (UFMG) em 2016 aponta que a cada 3 minutos, 2,47 brasileiros morrem em hospital público ou privado como consequência de um "erro" ou de um "evento adverso" relativo a erros de dosagem ou administração de medicamentos, uso incorreto de equipamentos, infecção hospitalar, etc. Para mudar este panorama é necessário investir na qualificação de processos e serviços, sendo que a medida mais importante neste sentido vem sendo a implementação de sistemas de acreditação hospitalar ${ }^{(2)}$.

Os processos de acreditação são baseados em padrões centrados no paciente, sendo a melhoria da qualidade de vida o objetivo principal de todo processo de qualificação. A incorporação da avaliação de indicadores de desempenho deve ser uma atividade continua e permanente, tendo por base a revisão de padrões e de manuais de acreditação, tornando o processo de qualificação mais 
dinâmico, efetivo e seguro, tanto para os pacientes quanto para os profissionais de saúde dos hospitais ${ }^{(3)}$.

A gestão da qualidade proporciona tanto a excelência no serviço e produtos, como a agregação de valores às organizações, visando à melhoria continua de seus processos e preparando os trabalhadores para as transformações do mercado no qual as empresas estão inseridas ${ }^{(4)}$. Os programas de acreditação hospitalar consistem em procedimentos de avaliação dos recursos institucionais, de maneira voluntária, periódica, reservada e sigilosa, que visa garantir a qualidade da assistência através de padrões previamente validados. Os padrões podem ser mínimos ou mais elaborados e exigentes, definindo diferentes níveis de satisfação e qualificação ${ }^{(5)}$.

Existem no Brasil várias instituições credenciadas para fornecer certificações, dentre elas podemos citar o Instituto Brasileiro para Excelência em Saúde IBESC, Instituto de Acreditação Hospitalar, Organização Nacional de Acreditação - ONA e Certificação em Saúde - IAHCS, Compromisso com a Qualidade Hospitalar - CQH e Fundação Carlos Alberto Vanzolini - FCAV. Dentre as instituições internacionais de acreditação merecem destaque Joint Commission International (JCI) (EUA), QHA Trent Accreditation (UK), Accreditation Canada (Canadá).

Os processos de acreditação costumam avaliar indicadores de desempenho, que são medidas indiretas da qualidade utilizadas como instrumento de acompanhamento e monitoramento de processos, serviços ou profissionais que podem estar apresentando problemas e que necessitam de uma avaliação mais direta. Os indicadores de desempenho são utilizados mais frequentemente em atividades de monitoramento externo, que assumem papel crescente como meio de fornecer visibilidade aos usuários e às agências financiadoras e reguladoras ${ }^{(6)}$. Além de subsidiar a tomada de decisão, o monitoramento por meio de indicadores é entendido enquanto prática reflexiva capaz de promover o aprendizado pessoal e institucional, melhoria contínua dos processos de gestão, maior transparência e responsabilização ${ }^{(7)}$.

Dentro do contexto hospitalar, o setor de farmácia é dotado de atividades voltadas para maximizar a terapia e minimizar risco de erros, contribuindo assim com o uso seguro e coerente de medicamentos ${ }^{(8)}$. Por meio da farmácia clínica pode-se identificar o erro na dose, tanto superior quanto inferior à necessária, duplicidade terapêutica, prescrição de medicamento não indicado para o paciente, em virtude de insuficiência renal e hepática, forma farmacêutica, via de administração, intervalo e taxa de infusão inadequado e ainda identificar os erros relacionados ao processo de elaboração da prescrição, tais como ilegibilidade, uso de abreviaturas, omissão de forma farmacêutica, concentração, via de administração, intervalo, erro na unidade do medicamento e outros ${ }^{(9)}$.

Até o momento, são escassas as referências na literatura especializada abordando especificamente a utilização de indicadores de desempenho para avaliação da assistência farmacêutica em ambiente hospitalar. Neste sentido, destaca-se a importância de descrever e implementar indicadores, adaptada às especificidades da gestão da assistência farmacêutica, contemplando questões 
relativas aos suprimentos e a farmácia clínica. O objetivo deste trabalho foi descrever um conjunto de indicadores de qualidade relativos à assistência farmacêutica, que podem ser úteis para a gestão da qualidade hospitalar.

\section{METODOLOGIA}

A presente pesquisa contemplou a observação de práticas relacionadas à assistência farmacêutica hospitalar e o planejamento da implementação de indicadores de desempenho, baseada em um contexto previamente estabelecido pela própria investigação, denominada como pesquisa-ação ${ }^{(10)}$. Considerando o objetivo da pesquisa, foi realizado, primeiramente, um levantamento descritivo, observacional e qualitativo, que serviu para a determinação de indicadores de desempenho que pudessem representar mudanças de paradigmas para a melhoria dos processos e serviços.

Os dados foram coletados a partir da investigação de relatórios físicos e virtuais disponibilizados pela instituição, um hospital filantrópico da região central do Rio Grande do Sul, e observação das rotinas relativas à assistência farmacêutica hospitalar. A partir destes resultados, foram sugeridos os seguintes indicadores de desempenho: padronização de medicamentos, consumo médio mensal, estoque mínimo, ponto de ressuprimento, devoluções de materiais e medicamentos, logística adequada dos medicamentos, padronização de receituários e notas de sala, capacitação de $\mathrm{RH}$, participação em comissões, cumprimento aos procedimentos operacionais padrão (POPs) e conciliação medicamentosa.

Dados adicionais foram coletados a partir de diálogos não formais com os funcionários que atuam em interface com a assistência farmacêutica hospitalar, ou seja, funcionários da farmácia hospitalar e da gestão. Os indicadores sugeridos pela pesquisa e que foram considerados apropriados segundo a avaliação da gestão, foram implementados pela gestão da qualidade do hospital. O presente trabalho foi submetido ao comitê de ética do Centro Universitário Franciscano sendo aprovado sob registro CAAE 59501316.9.0000.5306.

\section{RESULTADOS}

\section{Período observacional}

Primeiramente foi realizada uma pesquisa observacional das rotinas, consulta a documentos, conversas indiretas com farmacêuticos e funcionários, com vistas a reconhecer as etapas vinculadas a assistência farmacêutica hospitalar, que serão descritas a seguir. 


\section{a) Dispensação de medicamentos e produtos médicos}

O sistema de distribuição de medicamentos padronizado no hospital prevê que a dispensação deve ser liberada individualmente, por paciente, por meio de prescrições e requisições informatizadas. Os médicos geram as prescrições de medicamentos e os enfermeiros fazem as requisições de produtos médicos e soluções fisiológicas de até $250 \mathrm{~mL}$ que são utilizadas em procedimentos de curativos. As prescrições e requisições são atendidas pelos colaboradores da farmácia com a supervisão do profissional farmacêutico. Inicialmente, é feita uma análise da prescrição e da requisição, para a avaliação e/ou correção eventuais erros, tais como quantidades inadequadas, cálculo de dose, erros de digitação, medicação não padronizada pelo hospital e medicação de uso coletivo que não é dispensada pela farmácia. Depois das prescrições e requisições serem atendidas no sistema, as mesmas são impressas e todos os produtos médicos e medicamentos são reunidos, confirmados e processados com leitor de código de barras. A partir daí, são repassados para o posto central de enfermagem, onde são armazenados para liberação às unidades de internação por horário, para cada paciente. Para a unidade de pronto atendimento (UPA), que é uma unidade externa, os medicamentos e produtos médicos são entregues diretamente para a equipe de enfermagem.

\section{b) Dispensação por receituários manuais}

A equipe da enfermagem entrega para a farmácia a prescrição médica em três vias. O funcionário deve imediatamente verificar se a prescrição a ser dispensada contempla os seguintes itens: medicamento prescrito conforme a Denominação Comum Brasileira (DCB), prescrição legível, quantidades e dosagem adequadas, carimbo e assinatura do médico, nome completo do paciente e identificação do leito.

Depois da conferência do receituário separa-se os medicamentos requisitados, confirma-se cada produto no leitor de código de barra, lançando e processando os produtos para a conta do paciente, e por fim, libera-se para a posto central da enfermagem com duas vias (uma via permanece no arquivo da farmácia). Caso haja dúvidas em quaisquer etapas deste procedimento, o farmacêutico deverá ser consultado.

\section{c) Devoluções de produtos médicos e medicamentos:}

Medicamentos e produtos médicos não utilizados pelo paciente durante o período de 24h deverão retornar à farmácia, na forma de devoluções. Estas, são realizadas por paciente e devem ser entregues à equipe da farmácia, de maneira individualizada, por requisição e com o número da devolução, sendo que os produtos deverão ser primeiramente devolvidos no sistema, com a conferência da quantidade e número de lote. As devoluções devem ser justificadas no sistema, sendo que as causas mais comuns deste procedimento são: alta hospitalar, recusa a utilização do medicamento, óbito, cancelamento 
do uso, entre outras justificativas cabíveis em cada caso. Se a farmácia receber devoluções com erros (número de lote, erros de quantidade ou não devolvidas no sistema) os medicamentos e materiais médicos devem retornar à unidade central de enfermagem para a correção do erro.

\section{d) Consumos das unidades hospitalares}

São chamados de "consumo" produtos médicos e medicamentos de uso coletivo para os pacientes ou funcionários, como por exemplo, luvas de procedimentos, pomadas para assadura, etc. O conjunto de materiais definido como "consumo" possui dia próprio para retirada e deve ser solicitado pelo enfermeiro responsável de cada unidade, com quantidade estabelecida pelo livro de consumo, elaborado pelo enfermeiro responsável de cada unidade e pelo farmacêutico, onde consta o que cada unidade pode solicitar e quantidades máximas que podem ser retiradas. O "consumo" também deve ter registro eletrônico.

\section{e) Padronização de medicamento ou produtos médicos}

Primeiramente deve-se preencher um formulário específico para padronização, onde devem constar o nome do produto e a justificativa para a padronização. 0 formulário é submetido à avalição da Comissão de Farmácia Terapêutica e para o setor de compras onde é aprovado ou recusado.

\section{f) Procedimentos operacionais padrão (POPs)}

Os POPs de cada atividade realizada na farmácia são disponibilizados em armário comum para os funcionários, que são orientados a ler e assinar registro de leitura. Dentre os principais POPs da farmácia hospitalar, pode-se citar o POP recebimento de mercadoria; POP fracionamento de medicamentos; POP controle de temperatura e umidade; POP controle de temperatura da geladeira, entre outros.

\section{g) Medicamentos controlados}

São fracionados somente pelos farmacêuticos e conferidos no final de cada turno. Cada retirada, entrada e devolução dos medicamentos controlados dos armários são registrados em livro próprio com a data, quantidade e nome do responsável pelo procedimento.

h) Fracionamentos e etiquetagem de medicamentos 
O fracionamento possui sala própria, onde cada medicamento que é fracionado é registrado no livro de fracionamento com o nome genérico, fabricante, data de validade, número do lote, quantidade antes do fracionamento, quantidade fracionada, quantidade após o fracionamento, data do fracionamento, nome do responsável e número sequencial do livro de fracionamento. Cada medicamento fracionado deve conter uma etiqueta de identificação. As etiquetas devem conter número do lote, número do fracionamento do livro, nome genérico, dosagem, número de registro no conselho regional do farmacêutico responsável e código de barra.

\section{i) Etiquetagem de medicamentos e produtos médicos}

Todos os medicamentos e produtos médicos devem receber etiqueta com código de barra e com o nome do produto, para que se garanta a rastreabilidade.

\section{j) Kits maternidade e ambulatório}

Existem diferentes tipos de kits que são utilizados pelo centro obstétrico e maternidade, de acordo com o tipo de parto e o tipo de medicamentos e produtos médicos que são necessários. Os kits do ambulatório podem ser de quatro tipos: colonoscopia, endoscopia, microcirurgia e cirurgia buco-maxilar. Todos estes kits devem ser conferidos e lançados na conta do paciente, conforme nota de sala. Observa-se a importância do preenchimento adequado das notas de sala para o controle destes produtos.

\section{k) Livro de pedidos de compra}

O livro de pedidos de compra é acessível a todos os funcionários, sendo que aquele que abre a última caixa de determinado produto ou percebe a sua falta deve registrar o nome do produto no livro para o encaminhamento da aquisição.

\section{I) Atividades do farmacêutico}

Dentre as principais atividades do farmacêutico, pode-se citar a entrada de notas, conferência de medicamentos controlados, resposta às dúvidas de funcionários, equipe de enfermagem e médicos, registro de temperatura e ambiente, registro de temperatura da geladeira, participação em comissões, pedidos eletrônicos de mercadoria, baixa do estoque de produtos vencidos e avariados, dispensação e controle de medicamentos e produtos médicos, coordenação técnica nas ações relacionadas à padronização, programação, seleção e aquisição de medicamentos, cumprir a legislação vigente relativa ao armazenamento, conservação, controle de estoque de medicamentos, produtos 
para a saúde, saneantes e insumos, bem como normas relacionadas com a distribuição e utilização dos mesmos e elaboração de manuais técnicos.

\section{m) Comissões}

O hospital possui sete comissões com participação de farmacêutico, sendo que em todas elas, o participante é o diretor técnico farmacêutico do hospital. As reuniões de todas as comissões são realizadas uma vez por mês e com pautas preestabelecidas, para que se obtenha melhor aproveitamento das discussões e decisões. Todas as reuniões possuem livro ata, que são assinados por todos os presentes. As sete comissões que possuem participação do farmacêutico são: Comissão de Farmácia e Terapêutica (CFT), Comissão de Avaliação de Feridas (CAF), Comissão Nutricional (CN), Comissão Transfusional (CT), Comissão de Segurança do Paciente (CSP), Comissão de Biossegurança (CB) e Comissão de Controle de Infecção Hospitalar (CCIH).

\section{Determinação de indicadores}

A Tabela 1 descreve os indicadores de qualidade para o hospital em estudo, com foco na qualificação da assistência farmacêutica hospitalar, contemplando o nome do indicador, o parâmetro observado, a fonte de evidência e estabelecimento de metas a serem cumpridas. 
Tabela 1. Sugestão de indicadores de desempenho relativos à assistência farmacêutica hospitalar.

\begin{tabular}{|c|c|c|c|c|}
\hline Indicador & Parâmetro & $\begin{array}{l}\text { Fonte de } \\
\text { evidência }\end{array}$ & Meta & Objetivo \\
\hline $\begin{array}{l}\text { Padronização } \\
\text { dos } \\
\text { medicamentos } \\
\text { e produtos } \\
\text { médicos }\end{array}$ & $\begin{array}{l}\text { Existência de } \\
\text { comissão } \\
\text { farmacoterapêutica } \\
\text { multiprofissional } \\
\text { atuante, com } \\
\text { reuniões periódicas }\end{array}$ & $\begin{array}{l}\text { Lista de } \\
\text { medicamentos } \\
\text { e produtos } \\
\text { médicos } \\
\text { padronizados }\end{array}$ & $\begin{array}{l}\text { Construção e } \\
\text { atualização } \\
\text { mensal da lista } \\
\text { de } \\
\text { medicamentos e } \\
\text { produtos } \\
\text { médicos } \\
\text { padronizados }\end{array}$ & $\begin{array}{l}\text { A padronização de } \\
\text { medicamentos tem } \\
\text { como objetivos } \\
\text { principais a } \\
\text { otimização do } \\
\text { atendimento ao } \\
\text { paciente através da } \\
\text { seleção racional de } \\
\text { medicamentos, o } \\
\text { aumento da } \\
\text { qualidade da } \\
\text { farmacoterapia, a } \\
\text { garantia da segurança } \\
\text { na prescrição e } \\
\text { administração do } \\
\text { medicamento, } \\
\text { disciplina do } \\
\text { receituário e } \\
\text { uniformidade da } \\
\text { terapêutica, a } \\
\text { redução no custo da } \\
\text { terapêutica, sem } \\
\text { prejuízos para a } \\
\text { segurança e a } \\
\text { efetividade do } \\
\text { tratamento, a } \\
\text { diminuição da } \\
\text { quantidade de } \\
\text { produtos, a redução } \\
\text { dos custos com } \\
\text { estoques de } \\
\text { medicamentos que } \\
\text { apresentem o mesmo } \\
\text { fim terapêutico, } \\
\text { assim como a } \\
\text { simplificação das } \\
\text { rotinas de aquisição, } \\
\text { armazenamento, } \\
\text { dispensação e } \\
\text { controle (11) }\end{array}$ \\
\hline $\begin{array}{l}\text { Consumo Médio } \\
\text { Mensal (CMM) }\end{array}$ & $\begin{array}{l}\text { Relatório com } \\
\text { informações } \\
\text { atualizadas sobre } \\
\text { consumo físico de } \\
\text { produtos }\end{array}$ & $\begin{array}{l}\text { Calculado a } \\
\text { partir da } \\
\text { demanda por } \\
\text { produto. } \\
\mathrm{CMM}= \\
\underline{\mathrm{C} 1+\mathrm{C} 2+\ldots}\end{array}$ & $\begin{array}{l}\text { Determinação do } \\
\text { CMM para cada } \\
\text { item constante } \\
\text { da padronização }\end{array}$ & $\begin{array}{l}\text { Realizar uma efetiva } \\
\text { gestão de estoques se } \\
\text { faz necessário para } \\
\text { que controlar os } \\
\text { recursos investidos e } \\
\text { evitar a falta de } \\
\text { produtos na cadeia } \\
\text { de suprimentos. A } \\
\text { coleta de dados como }\end{array}$ \\
\hline
\end{tabular}




\begin{tabular}{|c|c|c|c|c|}
\hline & & $\begin{array}{l}\text { Onde: } \\
\mathrm{C}=\text { consumo } \\
\text { por mês } \\
\mathrm{n}=\text { número de } \\
\text { meses }\end{array}$ & & $\begin{array}{l}\text { consumo médio } \\
\text { mensal permite a } \\
\text { tomada de decisão } \\
\text { coerente para a } \\
\text { logística hospitalar }\end{array}$ \\
\hline $\begin{array}{l}\text { Estoque Mínimo } \\
\text { (EM) }\end{array}$ & $\begin{array}{l}\text { Produto disponível } \\
\text { em tempo oportuno }\end{array}$ & $\begin{array}{l}\text { Cálculo } \\
\text { EM=CMM x K } \\
\text { Onde: } \\
\text { EM = Estoque } \\
\text { mínimo } \\
\text { CMM = } \\
\text { Consumo } \\
\text { médio mensal } \\
\text { K = Fator de } \\
\text { correção } \\
\text { Observação: } \\
\text { para K, caso } \\
\text { queiramos ter } \\
\text { uma falha de } \\
\text { apenas } 10 \% \text { no } \\
\text { estoque, será } \\
\text { usado o valor } \\
\text { de } 0,9 \text {. }\end{array}$ & $\begin{array}{l}\text { Estabelecimento } \\
\text { de estoque } \\
\text { mínimo para } \\
\text { cada produto } \\
\text { padronizado }\end{array}$ & $\begin{array}{l}\text { Estoque mínimo tem } \\
\text { o objetivo manter a } \\
\text { menor quantidade de } \\
\text { material no estoque } \\
\text { capaz de atender a } \\
\text { um consumo superior } \\
\text { ao estimado para } \\
\text { certo período de } \\
\text { tempo ou para } \\
\text { atender a demanda } \\
\text { normal em caso de } \\
\text { atraso de entrega da } \\
\text { nova aquisição }\end{array}$ \\
\hline $\begin{array}{l}\text { Ponto de } \\
\text { ressuprimento } \\
\text { (pr) ou ponto de } \\
\text { pedido (pp) }\end{array}$ & $\begin{array}{l}\text { Produto disponível } \\
\text { em tempo oportuno. }\end{array}$ & $\begin{array}{l}\mathrm{PR}=\mathrm{C} \times \mathrm{TR}+\mathrm{EM} \\
\text { Onde: } \\
\text { C: Consumo } \\
\text { médio mensal/ } \\
\text { dia } \\
\text { TR: Tempo de } \\
\text { reposição em } \\
\text { dias } \\
\text { EM: Estoque } \\
\text { mínimo }\end{array}$ & $\begin{array}{l}\text { Estabelecimento } \\
\text { do ponto de } \\
\text { ressuprimento } \\
\text { para cada } \\
\text { produto } \\
\text { padronizado }\end{array}$ & $\begin{array}{l}\text { O ponto de } \\
\text { ressuprimento tem } \\
\text { como objetivo } \\
\text { identificar o número } \\
\text { de unidades } \\
\text { presentes no estoque } \\
\text { no momento em que } \\
\text { deverá ser emitido } \\
\text { um novo pedido ao } \\
\text { fornecedor (14) }\end{array}$ \\
\hline $\begin{array}{l}\text { Devoluções de } \\
\text { materiais e } \\
\text { medicamentos }\end{array}$ & $\begin{array}{l}\text { Número de } \\
\text { devoluções/período }\end{array}$ & $\begin{array}{l}\text { Lista de } \\
\text { número de } \\
\text { devoluções por } \\
\text { dia com } \\
\text { justificativa }\end{array}$ & $\begin{array}{l}\text { Redução no } \\
\text { número de } \\
\text { devoluções por } \\
\text { dia }\end{array}$ & $\begin{array}{l}\text { Avaliar a devolução } \\
\text { conforme justificativa } \\
\text { para planejamento e } \\
\text { implementação de } \\
\text { possíveis } \\
\text { intervenções. }\end{array}$ \\
\hline $\begin{array}{l}\text { Logística } \\
\text { adequada de } \\
\text { medicamentos }\end{array}$ & $\begin{array}{l}\text { Medicamento ou } \\
\text { produto médico } \\
\text { corretamente } \\
\text { destinado e entregue }\end{array}$ & $\begin{array}{l}\text { Lista de } \\
\text { medicamentos } \\
\text { ou produtos } \\
\text { médicos } \\
\text { notificados à } \\
\text { farmácia com } \\
\text { destino } \\
\text { incorreto }\end{array}$ & $\begin{array}{l}\text { Redução no } \\
\text { número de } \\
\text { devoluções, } \\
\text { perda e atraso de } \\
\text { administração }\end{array}$ & $\begin{array}{l}\text { Este indicador tem } \\
\text { como objetivo } \\
\text { principal favorecer a } \\
\text { diminuição dos erros } \\
\text { de entregas, perda de } \\
\text { pastas, atraso na } \\
\text { administração e } \\
\text { perda de tempo da } \\
\text { equipe de }\end{array}$ \\
\hline
\end{tabular}




\begin{tabular}{|c|c|c|c|c|}
\hline & & & & enfermagem \\
\hline $\begin{array}{l}\text { Padronização de } \\
\text { receituários e } \\
\text { notas de sala }\end{array}$ & $\begin{array}{l}\text { Preenchimento } \\
\text { padronizado de } \\
\text { receituário e notas } \\
\text { de sala }\end{array}$ & $\begin{array}{l}\text { Modelo de } \\
\text { padronização } \\
\text { de receituário } \\
\text { e notas de sala }\end{array}$ & $\begin{array}{l}\text { Segurança na } \\
\text { dispensação }\end{array}$ & $\begin{array}{l}\text { A padronização dos } \\
\text { receituários é de } \\
\text { fundamental } \\
\text { importância para a } \\
\text { correta e segura } \\
\text { dispensação de } \\
\text { medicamentos e } \\
\text { produtos médicos. Os } \\
\text { receituários devem } \\
\text { ser padronizados com } \\
\text { o nome da medicação } \\
\text { pela Denominação } \\
\text { Comum Brasileira } \\
\text { (DCB), com } \\
\text { quantidades, doses e } \\
\text { via de administração } \\
\text { correta, possuir letra } \\
\text { legível, carimbo do } \\
\text { médico e nome } \\
\text { completo do paciente }\end{array}$ \\
\hline $\begin{array}{l}\text { Capacitação de } \\
\text { recursos } \\
\text { humanos }\end{array}$ & $\begin{array}{l}\text { Recursos humanos } \\
\text { (RH) capacitados } \\
\text { para o } \\
\text { desenvolvimento das } \\
\text { atividades de } \\
\text { assistência } \\
\text { farmacêutica } \\
\text { hospitalar }\end{array}$ & $\begin{array}{l}\text { Registro de } \\
\text { atividades de } \\
\text { educação } \\
\text { permanente }\end{array}$ & $\begin{array}{l}\text { Aumento } \\
\text { gradativo de } \\
\text { profissionais } \\
\text { capacitados }\end{array}$ & $\begin{array}{l}\text { O setor de RH deve } \\
\text { manter os } \\
\text { profissionais atuantes } \\
\text { da farmácia } \\
\text { hospitalar atualizados } \\
\text { e capacitados para as } \\
\text { atividades } \\
\text { relacionadas à } \\
\text { assistência } \\
\text { farmacêutica } \\
\text { hospitalar. A } \\
\text { educação } \\
\text { permanente faz como } \\
\text { que o funcionário se } \\
\text { mantenha motivado } \\
\text { para replicar seus } \\
\text { conhecimentos para } \\
\text { os demais colegas }\end{array}$ \\
\hline $\begin{array}{l}\text { Participação em } \\
\text { comissões }\end{array}$ & $\begin{array}{l}\text { Participação e } \\
\text { atuação dos } \\
\text { farmacêuticos em } \\
\text { comissões } \\
\text { institucionais }\end{array}$ & $\begin{array}{l}\text { Número de } \\
\text { farmacêuticos } \\
\text { envolvidos em } \\
\text { comissões } \\
\text { dividido pelo } \\
\text { número total } \\
\text { de } \\
\text { farmacêutico }\end{array}$ & $\begin{array}{l}\text { Aumento } \\
\text { gradativo do } \\
\text { número de } \\
\text { profissionais } \\
\text { envolvidos em } \\
\text { comissões } \\
\text { hospitalares }\end{array}$ & $\begin{array}{l}\text { A participação em } \\
\text { comissões é de } \\
\text { extrema importância } \\
\text { para se obter } \\
\text { melhoria no sistema } \\
\text { de qualidade de } \\
\text { serviço e processo } \\
\text { tanto para o paciente } \\
\text { como para o } \\
\text { profissional da área } \\
\text { de saúde. O número } \\
\text { de farmacêutico } \\
\text { efetivos no hospital }\end{array}$ \\
\hline
\end{tabular}




\begin{tabular}{|c|c|c|c|c|}
\hline & & & & $\begin{array}{l}\text { deve ser dividido pelo } \\
\text { o número de } \\
\text { comissões presentes, } \\
\text { com o objetivo de } \\
\text { tornar participativo } \\
\text { esse profissional para } \\
\text { futuras discussões } \\
\text { internas de melhoria }\end{array}$ \\
\hline $\begin{array}{l}\text { Cumprimento } \\
\text { aos POPs }\end{array}$ & $\begin{array}{l}\text { Procedimento } \\
\text { Operacionais padrão } \\
\text { escritos e atualizados } \\
\text { para } \\
\text { todas as atividades } \\
\text { desempenhadas }\end{array}$ & $\begin{array}{l}\text { Avaliação } \\
\text { qualitativa e } \\
\text { revisão } \\
\text { periódica dos } \\
\text { POPs } \\
\text { estabelecidos }\end{array}$ & $\begin{array}{l}\text { Avaliação } \\
\text { periódica dos } \\
\text { POPs. }\end{array}$ & $\begin{array}{l}\text { Procedimento } \\
\text { operacional padrão } \\
\text { (POPs) são instruções } \\
\text { detalhadas descritas } \\
\text { com o objetivo de } \\
\text { alcançar a } \\
\text { uniformidade na } \\
\text { execução de uma } \\
\text { função específica. } \\
\text { Proporcionando } \\
\text { segurança no } \\
\text { processo e } \\
\text { minimização de erros }\end{array}$ \\
\hline $\begin{array}{l}\text { Conciliação } \\
\text { medicamentosa }\end{array}$ & $\begin{array}{l}\text { Revisão dos aspectos } \\
\text { farmacológicos da } \\
\text { atenção } \\
\text { farmacêutica, no que } \\
\text { tange à busca ativa } \\
\text { por problemas } \\
\text { relacionados a } \\
\text { medicamentos }\end{array}$ & $\begin{array}{l}\text { Percentual de } \\
\text { prescrições } \\
\text { checadas pelo } \\
\text { farmacêutico } \\
\text { por } \\
\text { determinado } \\
\text { período }\end{array}$ & $\begin{array}{l}\text { Redução do } \\
\text { número de } \\
\text { problemas } \\
\text { relacionados a } \\
\text { medicamentos } \\
\text { que atingem o } \\
\text { paciente. }\end{array}$ & $\begin{array}{l}\text { O objetivo da revisão } \\
\text { da farmacoterapia é } \\
\text { detectar e prevenir } \\
\text { prováveis eventos } \\
\text { adversos e potenciais } \\
\text { relacionados a } \\
\text { medicamentos } \\
\text { produzidos por erros } \\
\text { de medicação. }\end{array}$ \\
\hline
\end{tabular}




\section{DISCUSSÃO}

Segundo estudo realizado na Universidade do Rio de Janeiro (2016) os indicadores de desempenho subsidiam a tomada de decisão dos gestores frente à identificação de resultados insatisfatórios. Entretanto, a utilização de indicadores não possui apenas caráter fiscalizador, mas atua como ferramenta educativa para o alcance de melhorias nos serviços ${ }^{(15)}$.

Em relação aos indicadores relativos à cadeia de suprimentos, foram sugeridos os cálculos ou determinações do "consumo médio mensal (CMM)", "estoque mínimo (EM)" e "ponto de ressuprimento (PR)" devido à sua fundamental importância para o monitoramento de um estoque seguro e eficiente. Lira (2013) cita que, mesmo que as informações estejam escassas e de acesso difícil, é importante adquiri-las de forma criativa, para que a falta de critérios técnicos não seja um fator complicador para uma boa programação de medicamentos e produtos médicos, ou mesmo gestão de estoques ${ }^{(17)}$. A determinação do "volume de devoluções de materiais e medicamentos" e "identificação da sua logística adequada" contribui para a racionalização dos recursos financeiros e garantia da disponibilidade destes produtos quando estes forem necessários.

Os cálculos desses indicadores são necessários para a realização de previsões de quantidades satisfatórias e reais para o atendimento aos usuários.

Dimensionar o estoque de segurança e o ponto de reposição tem o objetivo de melhorar o serviço e reduzir o descarte no meio ambiente por obsolescência ou perda por validade. Reduzindo o estoque, há uma redução dos investimentos financeiros, na compra de suprimentos, proporcionando a redução dos custos operacionais. Uma boa gestão de estoques baseada em indicadores de desempenho pode contribuir de modo decisivo para que os clientes do hospital não apenas tenham um bom serviço, mas também percebam o seu valor ${ }^{(18)}$.

O alto índice de devoluções encontrado em pesquisa de Araújo (2012), demostra que cerca de $25 \%$ dos mais de 4.000 itens dispensado ao mês, gera um importante volume de capital imobilizado de recursos econômicos parados durante a ineficiência do processo. Neste estudo conclui-se que a redução de devoluções e de erros no processo de dispensação de produtos médicos e medicamentos que acarretam um impacto significativo na operacionalização das atividades, uma vez que a implementação da metodologia na unidade em estudo não caracteriza ainda uma avaliação qualitativa dos processos ${ }^{(19)}$. Assim torna útil a utilização do indicador de "devoluções de medicamentos e produtos médicos" e "logística adequadas de medicamentos", para obter a qualificação dos processos.

Aspectos relativos ao planejamento e gestão da assistência farmacêutica são contemplados pelos indicadores de "padronização de medicamentos" e "conciliação medicamentosa", cuja importância reside no fato de que padronizar produtos abrigados e estoques é uma forma de normalização e auxilia na racionalização dos custos. Padronizar implica em definir quais materiais médico-hospitalares e medicamentos devem ser mantidos em 
estoques. A racionalização do estoque só é possível por meio da aplicação de regras para o tratamento ordenado de uma atividade específica e fundamental para a adequada utilização dos mesmos pela instituição de saúde (20).

A "conciliação medicamentosa" consiste na monitorização terapêutica, analisando a posologia, a interação do medicamento com outros fármacos, com alimento ou com alguma patologia, a via de administração, a indicação terapêutica e os efeitos adversos. Essa avaliação poderá resultar em uma intervenção farmacêutica, relacionada ao tratamento medicamentoso e/ou no monitoramento de doenças. O monitoramento de indicadores relativos a farmácia clínica contribui para a obtenção de informações mais específicas sobre a qualidade dos serviços farmacêuticos prestados (21).

No setor saúde, os programas de qualidade têm forte tendência a enfatizar a avaliação das condições dos hospitais, focalizados na infraestrutura, nos processos e resultados. A garantia da qualidade pode ser representada pelos indicadores "capacitação de recursos humanos", "cumprimento aos POPs", "padronização de notas de sala" e "participações em comissões". Todos estes indicadores têm por função a qualificação dos processos de trabalho, fundamental para o aprimoramento dos serviços. A melhoria da qualidade hospitalar é estabelecida por meio de padrões, resultado dos estudos de séries históricas na mesma organização ou de comparação com outras organizações semelhantes, em busca do defeito zero - situação que, embora não atingível na prática, orienta e filtra toda ação e gestão da qualidade (22).

Segundo estudo realizado em uma unidade básica de saúde em Porto Alegre (2007) avaliou 3.701 prescrições, 18\% apresentaram algum tipo de erro. Foram encontrados 3.519 erros somatórios, considerando que uma mesma prescrição apresentou mais de um erro, a média de erro por prescrição foi de $5,3{ }^{(23)}$. Justificando a proposta do indicador padronização de receituários e notas de sala, o farmacêutico é responsável por analisar as prescrições e só pode aviar ou dispensar os medicamentos quando todos os itens da receita estiverem devidamente preenchidos. Assim devem estar preenchidas de forma legível, com a quantidade escrita em algarismos arábicos e por extenso, sem emenda ou rasura. Também devem estar preenchidos o nome completo do paciente e a data de emissão. Dessa forma, esse indicador tem por objetivo analisar a observância da norma legal, estabelecida pela Lei Federal no 9.787/99 de

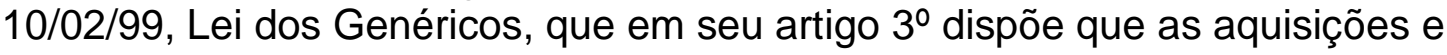
prescrições realizadas no âmbito do SUS devem utilizar a Denominação Comum Brasileira (DCB), permitindo, portanto, avaliar o cumprimento da legislação pelos prescritores locais ${ }^{(24)}$.

Neste estudo verificou-se a importância da implementação de educação continuada e a avaliação dos processos na rotina hospitalar por meio de ações educativas que contemplem, além dos aspectos técnico-científico, temas sobre ética e humanização em busca do desenvolvimento integral dos grupos profissionais, constituído por médicos, farmacêuticos, enfermeiros e outros. Neste contexto, torna-se indispensável a implementação de indicadores de qualidade junto a acreditação hospitalar, proporcionando um serviço de qualidade, suprindo as necessidades da população e valorização do profissional da área de saúde. 


\section{CONCLUSÃO}

Levando-se em conta o objetivo da pesquisa, foi apontada a real importância dos indicadores junto ao programa de acreditação, que agregam valor às decisões e conferem segurança as rotinas hospitalares, capaz de tornar o processo de identificação, análise e determinação, um processo racional e participativo aos gestores e funcionários. Conclui-se que os indicadores de desempenho estão intimamente relacionados a garantia da qualidade e excelência nos serviços de saúde, sendo notável a importância dos indicadores construídos neste trabalho, podendo ser aliados fiéis para as instituições, gestores, funcionários e usuários.

\section{REFERÊNCIAS}

1. BOHOMOL, E; RAMOS, L H. Erro de medicação: importância da notificação no gerenciamento da segurança do paciente. Revista Brasileira Enfermagem. 2007,60(1): 32-36.

2. COUTO, R; PEDROSA, T; ROSA, M. Erros acontecem: a força da transparência para o enfrentamento de eventos adversos assistenciais em pacientes hospitalizados. Instituto para práticas seguras no uso de medicamentos. Brasil, 2016.

3. RODRIGUES, E. Uma Revisão da Acreditação Hospitalar como Método de Avaliação de Qualidade e da Experiência Brasileira. Dissertação do Programa de Mestrado Profissional, Escola Nacional de Saúde Pública da Fundação Oswaldo Cruz/ MS. Março/2004.

4. MENEZES, J. O processo de acreditação hospitalar na perspectiva de profissionais de saúde de um hospital privado em Macapá. Estudo de caso. 2013.78f. Dissertação (Mestrado em Gestão). Escola de Ciências Econômicas e das Organizações, Universidade Lusófona de Humanidades e Tecnologias, Lisboa, 2013.

5. FELDMAN, L; GATTO, M; CUNHA, I C. História da evolução da qualidade hospitalar: dos padrões a acreditação. Acta Paul. Enferm. 2005, 18 (2): 213.

6. TRAVASSOS, C; NORONHA, J; MARTINS, M. Mortalidade hospitalar como indicador de qualidade: uma revisão. Ciência \& Saúde Coletiva. 1999, 2(4): 367-381.

7. COSTA, M; TOGEIRO, M; RIBEIRO, R. Importância da atuação de um profissional farmacêutico na farmácia de um hospital de pequeno porte. Faculdade de Pindamonhangaba. Pindamonhangaba, SP, 2013. 
8. COSTA, J; FELISBERTO, E; BEZERRA, L; CESSE, E; SAMICO, I. Monitoramento do desempenho da gestão da vigilância em saúde: instrumento e estratégia de uso. Ciência e Saúde Coletiva. 2013, 18 (5): 1201-1216.

9. PERINI, M; HESSEM, T; BOGUTCHI, M. Erros na prescrição hospitalar de medicamentos potencialmente perigosa. Revista Saúde Pública. 2009, 3(43):490-498.

10.TRIPP, D. Pesquisa-ação: uma introdução metodológica. Educação e pesquisa. 2005, 3 (31): 443-466.

11.SIMONETTI, V M M; NOVAES, M Lu O; GONÇALVES, A A. Seleção de medicamentos, classificação $A B C$ e redução do nível dos estoques da farmácia hospitalar. XXVII Encontro Nacional de Engenharia de Produção (EGENEP), Foz do Iguaçu, 2007.

12. LIRA, A B; NÓBREGA, F M; SOUSA, D F; DELMONDES M N; PEREIRA, $P$ C G; RIBEIRO, N K R; DINIZ, M F F M. Gestão de estoque: proposta para uma farmácia diferenciada. O Mundo da Saúde, São Paulo. 2013, 37(1): 97104.

13. NETO, J F M. Farmácia Hospitalar e suas interfaces com a saúde. Editora e Publicidade, 2005.

14.DE LIMA, J H G; DE CAMPOS, R R. Aplicação de conceitos da gestão de estoques para melhoria em sistema. Interface Tecnológica. 2013, 1 (10): 5568.

15. DE SOUZA, C, et al. Indicadores de qualidade utilizados no gerenciamento da assistência de enfermagem hospitalar [Healthcare quality indicators used in hospital nursing care management]. Revista Enfermagem UERJ. 2006, 6 (23): 787-793.

16. ROCHA, M A; CARNEIRO, P M; CASTILHO, S R. Estudo da utilização de medicamentos antimicrobianos de 2003 à 2004 em pacientes adultos em hospital terciário no Rio de Janeiro. Revista Brasileira de Farmácia. 2009, 1 (90): 50-53.

17. LIRA, A B et al. Gestão de estoque: proposta para uma farmácia diferenciada. O Mundo da Saúde, 2013.

18. SILVA, K S. Gerenciamento de farmácia hospitalar: Otimização da qualidade, produtividade e recursos financeiros. Revista Saúde e Desenvolvimento. 2016, 4(7):6-25.

19. ARAUJO, F J. Aplicação dos conceitos do DMAIC como estratégia de otimização de uma farmácia periférica: estudo de caso em um hospital de grande porte. XXXII encontro nacional de engenharia de produção Desenvolvimento Sustentável e Responsabilidade Social: As Contribuições da Engenharia de Produção Bento Gonçalves, RS, Brasil, 15 a 18 de outubro de 2012. 
20. DALLARMI, L. Gestão de suprimentos na farmácia hospitalar pública. Visão Acadêmica, 11(1), 2010.

21.FINATTO, R.B.; CAON, S.; BUENO, D. Intervenção farmacêutica como indicador de qualidade da assistência hospitalar. Rev. Bras. Farm. 93(3): 364-370, 2012

22.D'INNOCENZO M., ADAMI N.P, CUNHA I.C.K.O. O movimento pela qualidade nos serviços de saúde e enfermagem. Rev. Bras. Enferm. 59(1): 84-8, 2006.

23. GUZATTO, P.; BUENO, D. Análise de prescrições medicamentosas dispensadas na farmácia de uma unidade básica de saúde de Porto Alegre - RS. Revista HCPA, Porto Alegre. 2007, 27(3): 20-6.

24.BRASIL. Ministério da Saúde. Lei Federal no 9.787, de 10 de fevereiro de 1999. Dispõe sobre a vigilância sanitária, estabelece o medicamento genérico, dispõe sobre a utilização de nomes genéricos em produtos farmacêuticos e dá outras providências. Diário Oficial da União, Brasília, DF, 11 fev.1999. Seção I, p. 1-2.

Recebido: 18 de dezembro de 2017. Publicado: 19 de janeiro de 2018

Correspondência: Jaqueline Alves dos Santos. E-mail: jaquelinealves@unifra.edu.br

Conflito de Interesses: os autores declararam não haver conflito de interesses.

(c) This is an Open Access article distributed under the terms of the Creative Commons Attribution License, which permits unrestricted use, distribution, and reproduction in any medium, provided the original work is properly cited 